\title{
PENGUATAN ETIKA KEHUMASAN MELALUI REORIENTASI HUMAS PADA LEMBAGA PENDIDIKAN ISLAM
}

\author{
Abd Hamid Wahid \\ Univeristas Nurul Jadid, Probolinggo, Indonesia \\ Email :hamidw@gmail.com \\ Istianatul Hasanah \\ Univeristas Nurul Jadid, Probolinggo, Indonesia \\ Email : istianatulhasanah05@gmail.com
}

DOI: http://doi.org/10.33650/al-tanzim.v3i2.670

\begin{tabular}{l|l|l} 
Received: September 2019 & Revised: November 2019 & Approved: November 2019
\end{tabular}

\begin{abstract}
:
This paper presents the strengthening of public relations ethics through the reorientation of public relations in Islamic educational institutions, where public relations has an important role in managerial activities in Islamic educational institutions. In its implementation, the role of public relations in Islamic educational institutions is still underestimated and lacks the right portion in its application. $P R$ is only understood as a complementary administration in practice, thus causing educational institutions unable to manage good relations with the surrounding community as partners. This study uses a qualitative approach to the type of library research, where researchers want to clearly describe the object of study to be studied. Analysis of the data uses content analysis. The results of the study indicate that the reorientation of public relations in Islamic educational institutions must be based on; First, qaulan sadidan, Islamic educational institutions must convey factual and reliable information; Second, qaulan baligha, Islamic educational institutions communicate effectively, communicatively and easily understood; Third, qaulan ma'rufa, the communication process should avoid words that can offend partners / customers; Fourth, qoulan karima, public relations activities must respect partners, listen to aspirations and promote ethics; Fifth, Qaulan Layyina, public relations must be a friendship and friendship dissertation; Sixth, qaulan maysura, Islamic educational institutions must convey information that is easily understood and digested by the communicant.
\end{abstract}

Key words : Orientation, Public Relations, Islamic Education Institutions

\begin{abstract}
Abstrak
Tulisan ini menyajikan tentang penguatan etika kehumasan melalui reorientasi hubungan masyarakat dalam lembaga pendidikan Islam, di mana hubungan masyarakat memiliki peran penting dalam aktivitas manajerial pada lembaga pendidikan Islam. Dalam implementasinya, peran humas pada lembaga pendidikan Islam masih dipandang sebelah mata dan kurang mendapatkan porsi yang tepat dalam penerapannya. Humas hanya dipahami sebagai pelengkap administrasi saja dalam praktiknya, sehingga menyebabkan lembaga pendidikan tidak mampu mengelola hubungan yang baik dengan masyarakat sekitar sebagai mitranya. Penelitian ini menggunakan pendekatan kualitatif jenis library research, di mana peneliti ingin menggambarkan dengan jelas tentang obyek kajian yang akan diteliti. Analisis datanya menggukan content analisis. Hasil kajian menunjukkan bahwa, reorientasi humas dalam lembaga pendidikan Islam harus berdasarkan pada; Pertama, qaulan sadidan, lembaga pendidikan Islam harus menyampaikan informasi yang factual dan dapat dipercaya; Kedua,
\end{abstract}


qaulan baligha, lembaga pendidikan Islam berkomunikasi secara efektif, komunikatif dan mudah dipahami; Ketiga, qaulan ma'rufa, proses komunikasi hendaknya menghindari katakata yang bisa menyinggung para mitra/pelanggan; Keempat, qaulan karima, kegiatan kehumasan harus menghormati mitra, mendengarkan aspirasi dan mengedepankan etika; Kelima, Qaulan Layina, kehumasan harus disertasi keramahan dan bersahabat; keenam, qaulan maysura, lembaga pendidikan Islam harus menyampaikan informasi yang mudah dipahami dan dicerna oleh komunikan.

Kata Kunci : Orientasi, Humas, Lembaga Pendidikan Islam

\section{PENDAHULUAN}

Dalam perspektif Islam, komunikasi merupakan bagian integral dari kehidupan manusia (Munir, 2009), di mana komunikasi itu harus dilakukan dengan etika yang baik (Lubis, 2017). Islam memandang manusia dalam empat dimensi, di mana salah satu dimensinya adalah; manusia merupakan makhluk sosial yang membutuhkan orang lain yang harus melakukan komunikasi dan interaksi secara intens (Ismatulloh, 2017). Melalui komunikasi itu, manusia dapat mengekspresikan diri mereka dengan mendirikan jaringan dalam melakukan interaksi sosialnya dan mampu mengeksplorasi kepribadian yang ada di dalam diri mereka (Mukodi, 2011).

Dalam Islam, hubungan masyarakat atau public relations sangat identik dengan sebutan dakwah, yang berfungsi untuk memperkenalkan Islam kepada umat manusia dan juga sebagai pengantar Islam kepada masyarakat (Rahmawati, 2014). Manusia yang paling sukses dalam mensosialisasikan Islam kepada manusia yaitu Nabi Muhammad. Kunci sukses public relations Nabi yang bisa diterpakan adalah membangun kredibilitas atau kepercayaan. Ini bisa dilihat dari sejarahnya sebelum berdakwah, beliau telah dikenal sebagai insan yang memliki tingkat kejujuran yang tinggi di tengah-tengah masyarakat, sehingga ia disebut al-amin (Dahlan, 2014).

Nabi Muhammad memiliki keterampilan yang efektif dalam berkomunikasi, di mana pesan yang akan disampaikannya tertata rapi dan mampu memberikan pengaruh kepada lawan bicaranya. Nabi tidak hanya melakukan komunikasi secara verbal saja, tetapi mampu memberikan tauladan yang baik. Melalui public arelations yang beliau terapkan, mampu mensosialisasikan Islam secara kamil terhadap masyarakat dari berbagai etnis, suku dan golongan pada masanya (Fauzan, 2018).

Penelitian Afkarina (2018) menunjukkan bahwa public relations merupakan pusat kegiatan yang mencakup banyak bidang dan upaya di berbagai masyarakat antara hubungan manusia, hubungan kerja, hubungan manusia dengan alat dan media massa, keahlian dalam menggunakan dan memilih alat komunikasi dan media massa, seni mengajak diskusi dan musyawarah, seni mengundang untuk secara sadar mendekati dan menyelesaikan masalah, seni mengundang untuk secara sadar tertarik dan terpikat, untuk membeli, menggunakan, iklan, publisitas, keahlian untuk 
Al-Tanzim : Jurnal Manajemen Pendidikan Islam E-ISSN: 2549-5720 P-ISSN: 2549-3663

Vol. 03 No. 02 (2019) : 25-36

https:/ / ejournal.unuja.ac.id/ index.php/al-tanzim

menebak dan memperhitungkan situasi sosial, ekonomi, politik, keahlian, budaya.

Berangkat dari hal tersebut, peneliti tertarik untuk meneliti tentang reorientasi humas dalam lembaga pendidikan Islam, mengingat pentingnya humas bagi lembaga pendidikan Islam yang dipandang sebelah mata. Keunikan penelitian ini terletak pada reorientasi peran hubungan masyarakat atau public relations dalam kegiatan manajerial madrasah yang perlu diimplementasikan secara totalitas, untuk memperkuat jalinan kerjasa sama dan kemitraan lembaga dengan pihak lain.

\section{Prinsip dan Kaidah Kehumasan dalam Perspektif Islam}

Public relations merupakan fungsi manajemen yang membantu saluran komunikasi timbal balik, saling pengertian, mengendalikan dan kerja sama yang dibangun antara suatu organisasi dengan publik, mengangkat masalah manajemen, meningkatkan sebuah pengetahuan dan kewaspadaan terhadap pendapat orang, beserta mampu melayani dengan tanggung jawab terhadap kepentingan publik (Mulyono, 2011).

Membangun hubungan yang baik adalah pondasi awal sehingga akan lahir kesepahaman antara kedua pihak yang berkomunikasi juga menjadi unsur penting dari ajaran Islam. Karena alasan ini, ada banyak ayat dan tradisi yang mengingatkan umat Islam akan pentingnya menjaga hubungan baik dengan orang lain dalam Islam dapat diartikan sebagai keramahan maupun disebut sebagai silaturrahim.

Pengajaran ini sepaham dengan prinsip Public Relations (PR) yang mengutamakan saling menghargai kepentingan sehingga nantinya saling pengertian akan tercapai. Pemahaman tentang prinsip-prinsip PR dan nilainilai ajaran Islam yang ia yakini akan sangat memengaruhi pandangan mereka tentang praktik PR secara professional (Qoimah, 2018).

Kegiatan PR tidak bisa dilaksanakan secara asal-asalan, karena tujuan dari humas itu sendiri menentukan kemajuan organisasi yang saling berkaitan dengan kepentingan lainnya, biasanya disebut sebagai "audiens" atau publik. Dalam literatur Islam, kata "hubungan masyarakat" jarang dipakai dengan bahasa tertulis dan lisan, Namun, ada dua kata yang memiliki makna yang dekat dengan istilah itu, yaitu "habl" yang artinya "tali atau hubungan", dan "shîlah alrahim" (silaturahim) yang artinya "menghubungkan persaudaraan". Penggunaan kata habl dalam arti ini sesuai dengan firman Allah dalam QS. Ali Imran: 112

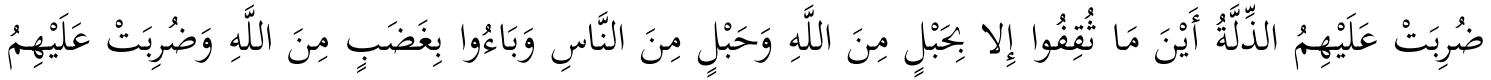

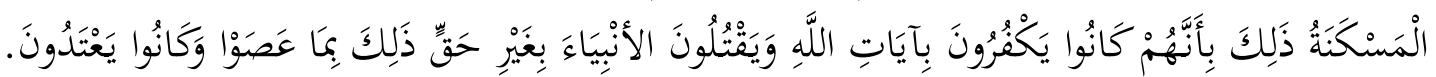


"Mereka diliputi kehinaan di mana saja mereka berada, kecuali jika mereka berpegang kepada tali (agama) Allah dan tali (perjanjian) dengan manusia, dan mereka kembali mendapat kemurkaan dari Allah dan mereka diliputi kerendahan. Yang demikian itu karena mereka kafir kepada ayat-ayat Allah dan membunuh para nabi tanpa alasan yang benar. Yang demikian itu disebabkan mereka durhaka dan melampaui batas."

Public relations dalam konsep pendidikan Islam mengajarkan bagaimana membangun hubungan baik dengan seseorang atau masyarakat yang berlandaskan pada Al-qur'an dan Hadis, sehingga prinsip-prinsip dan kaidahkaidah harus ditentukan sedemikian rupa agar nilai-nilai maupun aturan yang ada dalam Islam bisa diterapkan secara keselurah. Prinsip yang harus dibangun adalah kejujuran, adanya timbal balik yang saling menguntungkan terjadinya keseimbangan, serta mampu menjaga amanah yang diberikan dan yang terahir bekerja dangan tingkat keikhlasan yang tinggi (Fauzan, 2018).

Prinsip-prinsip hubungan manusia dalam Islam merujuk pada landasan filosofis yang sesuai dengan esensi harkat dan martabat manusia sebagai makhluk yang mulia, sehingga harus diperlakukan dengan bijak. Al-Quran memberikan instruksi yang sangat bijak dan manusiawi yang mengandung beberapa prinsip dasar yang perlu dipelajari dan dikembangkan (As-Suyuthi, 2011).

Keberhasilan Nabi Muhammad SAW dalam aktivitas public relations dapat itu digambarkan dalam sifat-sifat beliau sebagai kholifah, yang memiliki karakter; Pertama, Shiddiq (benar dan jujur). Dalam public relations sikap benar dan jujur sangat dibutuhkan dalam semua lembaga ataupun bagi seorang yang mempuyai tugas sebagai kehumasan untuk menyampaikan kenyataan yang sebenar-benarya tentang keadaan lembaga baik keluar masyarakat ataupun kedalam untuk kebaikan dan hendaknya seorang humas haruslah menerapkan suatu konsep di mana tidak boleh melakukan suatu promosi dengan propaganda yang mengandung unsur sara atau menyampaikan kenyataan yang tidak sesuai dengan keadaan untuk mengelabui konsumen, sebagaimana yang kita lihat pada era sekarang ini (Rahmawati, 2014).

Kedua, Amanah (dapat dipercaya). Sikap amanah sangat dibutuhkan dalam menejeman kehumasan pendidikan Islam, supaya tercipta kepercayaan untuk lembaga, orang-orang yang terikat dalam sebuah organisasi, baik menyangkut program dan implemintasinya, kemudian harus dibangun rasa saling perca, jangan curiga dan mencurigai, makadari itu amanah diperlukan.

Ketiga, Tabligh (menyampaikan atau komunikatif). Dalam public relations sikap yang tak kalah penting yaitu sikap tabligh, di mana saat melakukan komunikasi haruslah dengan cara yang benar seperti halus dalam kata-katanya, tidak menyakiti orang lain dalam penyampaikan sesuatu harus dengan tekhnik menyenangkan dan dengan cara lemmah lembut dalam tutur kata sehingga apa yang menjadi tujuan dapat diterima. 
Al-Tanzim : Jurnal Manajemen Pendidikan Islam E-ISSN: 2549-5720 P-ISSN: 2549-3663

Vol. 03 No. 02 (2019) : 25-36 https:// ejoumal.unija.ac.id/ index.php/al-tanzim

Keempat, Fathanah (Cerdas). Individu yang bertugas dalam kehumasan harus memiliki kecerdasan dalam menangkap informasi dan mampu menyampaikan suatu kepentingan dengan fenomena-fenomena yang ditemuinya di lapangan kepada orang lain. Artinya sifat fathanah penting dimiliki bagi yang berperan dalam lembaga apa pun. Fathanah artinya mengerti, memahami dan menghayati secara mendalam terhadap segala hal yang terjadi dalam tugas dan kewajiban.

Dalam hadits Nabi Muhammad SAW juga ditemukan prinsip-prinsip komunikasi yang lain dan bagaimana Rasulullah berkomunikasi, yaitu;

$$
\text { فليقل خيراً أو ليصمت , ورية رضي الله عنه أن رسول الله صلى الله عليه وسلم قال : من كان يؤمن بالله واليوم الاخر }
$$

Dari Abu Hurairoh RA, sesungguhnya Rasulullah SAW bersabda: "Barang siapa yang beriman kepada Allah dan hari akhirat, maka hendaklah ia berkata baik atau diam. Dan barang siapa yang beriman kepada Allah dan hari akhirat, maka hendaklah ia memuliakan tetangganya. Dan barang siapa yang beriman kepada Allah dan hari akhirat hendaklah ia memuliakan tamunya" (HR. Bukhori dan Muslim)

Hadits tersebut memiliki makna yang mendalam dalam aktivitas public relations. Prinsip yang ditetapkan dalam Hadits di atas adalah dasar etis untuk setiap Muslim, baik ketika dilaksanakannya suatu komunikasi, baik dalam menjalankan hubungan sehari-hari, berdakwah, dan dalam melakukan kegiatan lainnya.

Pesan Nabi SAW memiliki pengetahuan luas di mana dalam komunikasi harus ada kesesuaian dengan fakta. Maka seyogyanya PR itu selalu memperhatikan cara bicaranya, karena PR sangat identik dengan sebuah komunikasi, di mana komunikasi yang baik adalah komunikasi yang ada ketentuannya ada dalam al-qur`an dan apa yang sudah dicontohkan oleh Nabi.

Islam mamandang bahwasanya komukasi dalam kehidupan manusia merupakan bagian yang integral, di mana semua hal yang dilakukan pastilah bersanding dengan namanya komunikasi. Komunikasi yang harus diterapkan adalah komunikasi yang islami, yaitu komunikasi dengan karakter al-karimah atau etis yang pastinya berasal dari Alquran dan Hadits (Sunnah Nabi). Di mana komunikasi yang disebutkana akan mampu memunculkan kebaikan untuk diri sendiri maupun kebaikan untuk orang lain (Ismatulloh, 2017).

Dalam penerapannya, etika dalam kehumasan harus sesuai dengan prisip-prinsip agama yang sudah disebutkan di atas yaitu prinsip-prinsip agama yang bersumber dari Al-Qur'an dan al-Hadist, di mana orang yang memiliki tanggung jawab kehumasan harus mampu mengaplikasikan nilai- 
nilai yang terkandung dalam Al-Qur'an dan al-Hadist sebagai landasannya dan harus mampu memberikan suatu pelayanan yang dianggap nyaman dengan melakukan pekerjaan yang didasari ketulusan hati semata-mata untuk beribadah kepada Allah (Fauzan, 2018)

\section{PENGUATAN ETIKA KEHUMASAN MELALUI REORIENTASI HUMAS DALAM LEMBAGA PENDIDIKAN ISLAM}

Manajemen humas pada lembaga pendidikan Islam memberikan kontribusi yang sangat besar bagi keberlangsungan sebuah istitusi pendidikan khususnya dalam meningkatkan public image madrasah, karena pada hakikatnya prinsip mengerakkan organisasi ditekankan kepada pola interaksi antara seseorang dengan orang lain, dan sebagai jembatan antara institusi pendidikan dengan beberapa stakeholders yang ada, guna menciptakan keharmonian dalam public relations (Suhermanto \& Anshari, 2018).

Oleh karena itu, prinsip kehumasan yang telah digariskan dalam alQur'an dan al-Hadist harus menjadi pondasi dasar untuk melakukan konsolidasi dan koordinasi dengan pihak lain, utamanya dalam aspek pengelolaan lembaga pendidikan Islam (Mulyono, 2011). Prinsip dasar tersebut meliputi, prinsip keikhlasan dalam betindak dan beramal, ahlaqul karimah, koordinasi dan komunikasi, transparan dan terciptanya suatu ikatan yang sama-sama menguntungkan atau simbiotik mutualistic. Selain itu, manajemen humas harus disertai prinsip-prinsip yang telah diajaran oleh Rasulullah melalui sifat-sifat yang beliu tunjukkan dalam berinteraksi dengan orang lain, yang meliputi; sikap sihddiq, tabling, amanah dan, fathonah, sebagai patron untuk memperkuat jejaring dengan pihak internal dan eksternal.

Manajemen pendidikan Islam merupakan suatu aktifitas manajerial yang ada, guna memobilisasi dan memadukan segala sumber daya guna tercapainya sebuah tujuan dalam pendidikan Islam yang telah disepakati bersama sebelumnya. Sumber daya yang akan dimobilisasi haruslah dipadukan demi tercapainya tujuan pendidikan tersebut, yang meliputi apa yang disebut $3 \mathrm{M}$ (man, money, dan material). Semua itu tidak hanya terbatas yang ada di sekolah maupun madrasah atau pimpinan perguruan tinggi Islam lainnya, akan tetapi bersifat general (Kurniawan, 2006).

Reorientasi humas dalam lembaga pendidikan Islam yang harus diimplementasikan oleh lembaga pendidikan Islam harus berlandaskan pada sikap, etika humas yang selaras dengan ajaran Islam. Hal ini sebagaimana disampaikan oleh Nazarullah (2018), sebagai berikut;

Pertama, qaulan sadidan merupakan bentuk kegiatan kehumasan yang mengandung unsur yang baik, di mana komunikasi yang dilakukan oleh lembaga pendidikan Islam dengan mitranya harus mampu memberikan informasi yang benar, faktual, jujur, dan tidak ada rekayasa. 
Al-Tanzim : Jurnal Manajemen Pendidikan Islam

E-ISSN: 2549-5720 P-ISSN: 2549-3663

Vol. 03 No. 02 (2019) : 25-36

https:// ejoumal.unija.ac.id/ index.php/al-tanzim

Adapun dasar dari perilaku tersebut adalah firman Allah yang termaktub dalam QS. An-Nisa : 9;

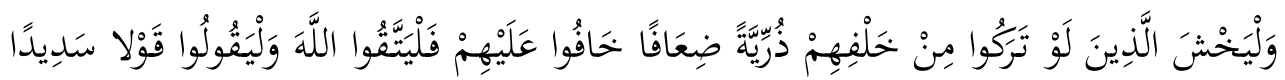

"Dan hendaklah takut kepada Allah orang-orang yang seandainya meninggalkan di belakang mereka anak-anak yang lemah, yang mereka khawatir terhadap (kesejahteraan) mereka. Oleh sebab itu hendaklah mereka bertakwa kepada Allah dan hendaklah mereka mengucapkan Qaulan Sadida - perkataan yang benar".

Ayat tersebut menjelaskan tentang pentingnya kejujuran dalam aktivitas manajerial pada lembaga pendidikan. kejujuran itu merupakan asas penting dalam public relations karena dalam menjalin hubungan dengan masyarakat, kejujuran merupakan tonggak utama untuk mendapatkan suatu kepercayaan masyarakat sehingga akan terciptanya atmosfer yang nyaman dalam aktivitas pendidikan (Dahlan, 2014).

Kedua, qaulan baligha, merupakan aktivitas kehumasan dalam lembaga pendidikan Islam yang harus dilakukan dengan efektif, sasarannya tepat, komunikatif, mudah dipahami, langsung pada intinya dan tidak bertele-tele. Komunikasi dalam hal ini harus tepat sasaran, gaya bicara dan pesan yang disampaikan harus menyesuaikan dengan tingkat kecerdasan komunikan dan dapat menggunakan bahasa yang mudah dimengerti oleh pendengar. Hal ini sesuai dengan firman Allah SWT dalam QS An-Nisa : 63;

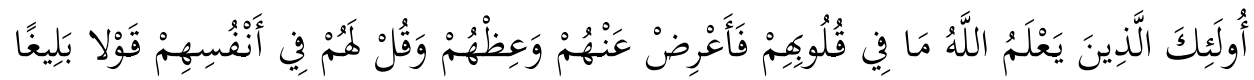

"Mereka itu adalah orang-orang yang Allah mengetahui apa yang (ada) di dalam hati mereka. Karena itu berpalinglah kamu dari mereka, dan berilah mereka pelajaran, dan katakanlah kepada mereka perkataan yang berbekas pada jiwa mereka." (QS: 4:63).

Al-Maraghi (1992) mempaparkan kata "qaulan baligha" dikaitkan dengan arti tabligh yang tabligh di sini adalah salah satu ciri Rasul yaitu Nabi Muhammad diamanahi dan berkewajiban menyerukan peringatan kepada umat-Nya dengan kata-kata yang menyentuh hati mereka (Ismatulloh, 2017). Qaulan baligha merupakan cara berkomunikasi dengan memberikan sebuah nasihat, di mana dalam peyampaian tentang penjelasan-penjelasan yang ada mampu memberikan pengaruh yang kuat kepada hati nuraninya, sehingga tergeraklah hatinya untuk memperbaiki akhlak dan akidahnya (Keller, 2013). 
Dalam hal ini, organisasi kehumasan pada lembaga pendidikan Islam harus dapat membaca keadaan masyarakat sekitarnya. Jika yang dihadapi merupakan masyarakat awam terhadap pendidikan, bahasa yang dipakai haruslah bahasa yang mudah dipahami atau menggunakan bahasa sederhana. Tetapi jika yang dihadapi adalah masyarakat intelektual, maka bahasa yang dipakai haruslah bahasa yang mampu memberikan kesan yang mendalam sehingga tercipta citra yang baik.

Ketiga, qaulan ma'rufa merupakan prinsip humas yang harus dilaksanakan oleh lembaga pendidikan Islam, terkait dengan bagaimana tata cara berkomunikasi yang baik antara pihak lembaga dengan masyarakat atau mitra. Dalam aktivitas ini, lembaga pendidikan Islam harus bersikap hati-hati dalam berkomunikasi dan harus menghindari kata-kata yang dapat menyinggung perasaan orang lain, khususnya para pelanggan atau mitra, karena mereka adalah sosok yang mampu memberikan manfaat yang sangat besar bagi keberlangungan lembaga (Muhammad Hasby Ash-Shiddiieqy, 2011).

Sikap yang harus ditunjukkan dalam aspek Qaulan ma`rufa dijelaskan dalam QS. An-Nissa : 5;

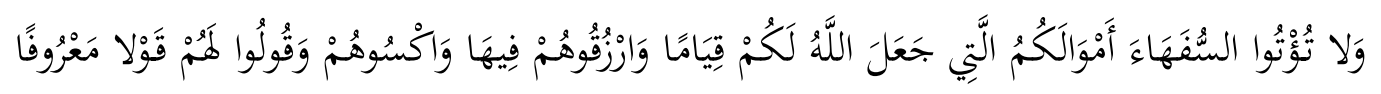

"Dan janganlah kamu serahkan kepada orang-orang yang belum sempurna akalnya, harta (mereka yang ada dalam kekuasaanmu) yang dijadikan Allah sebagai pokok kehidupan. Berilah mereka belanja dan pakaian (dari hasil harta itu) dan ucapkanlah kepada mereka kata-kata yang baik."

Ayat tersebut menjelaskan tentang keharusan bagi seorang wali dari anak-anak yatim dan wali orang yang safih (belum sempurna akalnya) hendaknya menjaga dan memelihara harta-harta mereka. Di mana menurut Hasbi, di sini melarang para wali dalam memberikan harta kepada mereka jika pemberian harta tersebut tidak mendatangkan maslahat (Ismatulloh, 2017).

Keempat, qaulan karima, yaitu aktivitas yang harus dijalankan dan dipraktikkan oleh lembaga pendidikan Islam dalam menjalin kerjasama dengan mitranya dalam hal memuliakaan lawan bicara, disertai dengan rasa hormat dan mendengarkan apa yang menjadi saran dan masukannya.

Terkait dengan aktivitas yang harus ditampilkan pada kegiatan manajemen humas melalui qoulan karima sesuai dengan perintah Allah dalam QS. Al-Isra: 23; 
Al-Tanzim : Jurnal Manajemen Pendidikan Islam

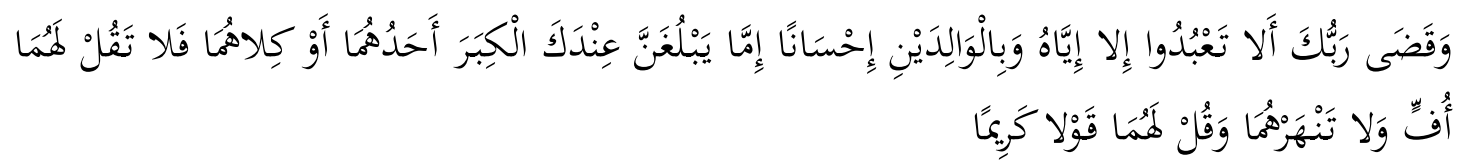

"Dan Tuhanmu telah memerintahkan supaya kamu jangan menyembah selain Dia dan hendaklah kamu berbuat baik pada ibu bapakmu dengan sebaik-baiknya. Jika salah seorang di antara keduanya atau kedua-duanya sampai berumur lanjut dalam pemeliharaanmu, maka sekali-kali janganlah kamu mengatakan kepada keduanya perkataan "ah" dan janganlah kamu membentak mereka dan ucapkanlah kepada mereka perkataan yang mulia"

Ayat tersebut menjelaskan tentang hal yang harus dilakukan pada saat sedang berbicara kepada kedua orang tua. Dalam hal ini, terdapat larangan untuk berbicara keras atau membentak, sehingga berdampak pada terlontarnya kata-kata yang mungkin membuat orang tua tersakiti. Orang tua dalam hal ini dapat juga dipahami sebagai mitra lembaga pendidikan. Dalam konteks kehumasan pada lembaga pendidikan Islam, qaulan karima memiliki makna penggunaan dan pemilihan kata-kata yang dianggap sopan, tidak kasar, tidak vulgar, dan harus menghindari kata-kata yang menyebabkan lawan bicara tersinggung. Qaulan karima merupakan ungkapan yang baik, indah, yang disertai penghormatan yang sesuai adab dan etika dalam kegiatan kehumasan dalam pendidikan yang harus diperhatikan ketika berkomunikasi dengan orang lain (Muhammad Hasby Ash-Shiddiieqy, 2011)

Kelima, qaulan layina, berarti berkomunikasi dengan lawan bicara atau mitra dengan menggunakan suara lembut, ramah dan bersahabat, sehingga bisa menyentuh hati. Terkait dengan hal tersebut, Allah SWT telah menjelaskan dalam QS. Thaha ayat : 44;

$$
\text { فَقُولا لَهُ قَوْلا لَيَّنًا لَعَلَّهُ يَتَذَكَّرُ أَوْ يحَشْىَى }
$$

"Maka berbicaralah kamu berdua kepadanya dengan kata-kata yang lemah lembut, mudah-mudahan ia ingat atau takut".

Ayat tersebut menunjukkan tentang pentingnya etika dan adab dalam berkomunikasi dan berinteraksi dengan mitra dalam konteks pendidikan. Diperlukan kehati-hatian dan penekanan bahwa bukan hanya sekedar lemah lembut dalam berbicara, akan tetapi bagaimana pembicaraan itu bisa diterima oleh lawan bicara dan memiliki kesan baik (Al-Maraghi, 1992).

Dengan menggunakan qaulan layina dalam kegiatan public relations pada lembaga pendidikan Islam, maka hati orang-orang yang berkomunikasi dengan lawan bicaranya akan merasa tersentuh dan jiwa mereka akan mampu menerima pesan komunikasi. Maka komunikasi yang Islami, haruslah 
menghindari kata-kata kasar dan bernada tinggi, sehingga mampu memberikan citra positif bagi lembaga.

Keenam, qaulan maysura, merupakan praktek kehumasan, di mana lembaga pendidikan Islam harus memberikan informasi yang jelas dan sejelasjelasnya kepada public, sehingga mudah dipahami dan dicerna oleh komunikan. Dalam hal ini, manajemen humas yang diterapkan oleh lembaga pendidikan Islam harus menggunakan berbagai saluran atau media yang bisa dijangkau dan didengar oleh masyarakat, agar supaya informasi yang disampaikan dapat diterima dengan baik dan terhindar dari multi tafsir.

\section{KESIMPULAN}

Public relations merupakan proses hubungan manusia satu sama lain yang berlangsung secara komunikatif dan manusiawi. Dalam aktivitas kehumasan pada lembaga pendidikan Islam, diperlukan pendekatan komunikasi yang tepat guna, agar supaya tujuan dari komunikasi itu dapat tercapai.

Sebagai tujuan akhir dari aktivitas public relations pada lembaga pendidikan Islam, yaitu terciptanya public interest dan public image yang positif, maka diperlukan ketekunan, keuletan dan kesungguhan dalam melaksanakan prinsip-prinsip kehumasan, mengingat penerpan humas yang baik akan mampu menciptakan kepercayaan masyarakat terhadap lembaga pendidikan meningkat. 
Al-Tanzim : Jurnal Manajemen Pendidikan Islam

E-ISSN: 2549-5720 P-ISSN: 2549-3663

Vol. 03 No. 02 (2019) : 25-36

bttps:/ / ejoumal.unuja.ac.id/ index.php/al-tanzim

\section{DAFTAR PUSTAKA}

Afkarina, N. U. R. I. (2018). Strategi Komunikasi Humas dalam Membentuk Public Opinion Lembaga Pendidikan. Jurnal Idaarah, 2(1), 50-63.

Al-Maraghi, A. M. (1992). Tafsir Al-Maraghi. Semarang: PT.CV.Toha Putra.

As-Suyuthi, J. (2011). Terjemah Tafsir Jalalain Berikut Asbabun Nuzulnya. Bandung: Sinar Baru Algensindo.

Dahlan, M. S. (2014). Etika Komunikasi dalam Al-Qur'an dan Hadits. Jurnal Dakwah Tabligh, 15(1), 115-123.

Fauzan. (2018). Etika Humas dalam Perspektif Islam: Tinjauan Epistimologis. Tadbir, 2(2), 135-154.

Ismatulloh, A. M. (2017). Etika Berkomunikasi dalam al-Qur'an: Analisis Penafsiran Hasbi ash-Shiddiqi dalam Tafsir an-Nur. Lentera, 1(2), 129146.

Keller, K. L. (2013). Conceptualizing, Measuring, and Managing CustomerBased Equity. Journal Marketing, 57(1), 1-22.

Kurniawan, S. (2006). Konsep Manajemen Pendidikan Islam Perspektif Al-Qur 'an dan al-Hadits. Nur El-Islam, 2(2), 1-34.

Lubis, L. (2017). Penerapan Prinsip-prinsip Komunikasi Islam dalam Mensukseskan Program KB di Rantau Prapat Kec. Rantau Selatan Kabupaten Labuhanbatu. AL-BALAGH, 1(2), 267-290.

Muhammad Hasby Ash-Shiddiieqy. (2011). Tafsir al-Qur'anul Majid An-Nur. Semarang: Pustaka Rizki Putra.

Mukodi. (2011). Nilai-nilai Pendidikan dalam Surat Luqman. Walisongo, 19(2), 429-450.

Mulyono. (2011). Teknik Manajemen Humas dalam Pengembangan Lembaga Pendidikan Islam. Ulumuna : Jurnal Studi Keislaman, 15(1), 165-184.

Munir. (2009). Kontribusi Teknologi informasi dan Komunikasi (TIK) dalam Pendidikan di Era Globalisasi Pendidikan Indonesia. Jurnal Pendidikan Teknologi Informasi Dan Komunikasi, 2(2), 1-4.

Nazarullah. (2018). Teori-Teori Komunikasi Massa dalam Perspektif Islam. Jurnal Peurawi, 1(1), 1-16.

Qoimah. (2018). Membangun Pelayanan Publik yang Prima: Strategi Manajemen Humas dalam Penyampaian Program Unggulan di Lembaga Pendidikan. Islamic Management: Jurnal Manajemen Pendidikan Islam, I(2), 191-206. 
Al-Tanzim : Jurnal Manajemen Pendidikan Islam

E-ISSN: 2549-5720 P-ISSN: 2549-3663

Vol. 03 No. 02 (2019) : 25-36

bttps:/ / ejournal.unuja.ac.id/index.php/al-tanzim

Rahmawati, Y. (2014). Manajemen Public Relations dalam Bisnis Islam. Salam: Jurnal Filsafat Dan Budaya Hukum, 1(2), 181-194.

Suhermanto, S., \& Anshari, A. (2018). Implementasi TQM Terhadap Mutu Institusi dalam Lembaga Pendidikan. Al-Tanzim: Jurnal Manajemen Pendidikan Islam, 2(1), 107-113. https://doi.org/10.33650/altanzim.v2i1.259 